\title{
Effects of HCG on human epithelial ovarian cancer vasculogenic mimicry formation in vivo
}

\author{
SAINAN GAO $^{1}$, CHAO FAN ${ }^{1}$, HUA HUANG $^{2}$, CHANGLAI ZHU $^{3}$, MIN SU $^{1}$ and YUQUAN ZHANG ${ }^{1}$ \\ Departments of ${ }^{1}$ Obstetrics and Gynecology, and ${ }^{2}$ Pathology, Affiliated Hospital of Nantong University; \\ ${ }^{3}$ Department of Electron Microscopy, Nantong University, Nantong, Jiangsu 226001, P.R. China
}

Received February 11, 2015; Accepted April 29, 2016

DOI: $10.3892 / 01.2016 .4630$

\begin{abstract}
Ovarian cancer is the leading cause of mortality due to gynecological malignancy, and vasculogenic mimicry (VM) formation is correlated with poor prognosis. In a previous study, the present authors observed that human chorionic gonadotropin (HCG) could promote VM formation in three-dimensional OVCAR-3 cell cultures. In order to investigate whether HCG could promote VM formation in ovarian cancer in vivo, the role of OVCAR-3 cells overexpressing or depleted of chorionic gonadotropin, beta polypeptide 5 (CGB5, which is the fifth subunit of $\beta-\mathrm{HCG}$ and was identified as the key part of HCG) were injected into nude mice in the present study, while BeWo cells were used as a positive control. The results demonstrated that overexpressed CGB5 promoted xenografts tumor formation in nude mice, and the results of hematoxylin and eosin and cluster of differentiation (CD)34-periodic acid-Schiff dual staining revealed that CGB5 promoted VM formation. Furthermore, reverse transcriptionpolymerase chain reaction and immunochemistry staining demonstrated that the expression of the vascular markers CD31, vascular endothelial growth factor and factor VIII was also upregulated in the CGB5-overexpressing xenografts tumors. In addition, the expression of luteinizing hormone receptor (LHR), the receptor of CGB5, was increased in CGB5-overexpressing cells. In conclusion, CGB5 may promote tumor growth and VM formation via activation of the LHR signal transduction pathway, which may support a novel strategy for ovarian cancer therapy.
\end{abstract}

Correspondence to: Dr Yuquan Zhang or Dr Min Su, Department of Obstetrics and Gynecology, Affiliated Hospital of Nantong University, 20 Xisi Road, Nantong, Jiangsu 226001, P.R. China E-mail: jsnt_zhangyuquan@ntu.edu.cn

E-mail: sumin_nt@126.com

Key words: human chorionic gonadotropin, chorionic gonadotropin, beta polypeptide 5, vasculogenic mimicry, ovarian cancer, in vivo

\section{Introduction}

Ovarian cancer is the leading cause of mortality due to gynecological malignancy in recent years (1). Although the diagnosis and treatments of ovarian cancer are constantly under development, the prognosis of the patients remains poor, which is due to the biological behavior of the tumor (2). Ovarian cancer cells are able to migrate and invade into the peritoneal/pelvic cavity. Therefore, clarification of the mechanisms of cell migration and invasion is important to identify novel therapy methods for ovarian cancer treatment.

Blood supply is essential for tumors metastasis (3). Previous studies have suggested that the development of tumor microcirculation appears to be a rate-limiting step for metastasis (3-5). In 1999, Maniotis et al (6) identified a novel phenomenon in the biology of tumor vascularization known as vasculogenic mimicry (VM). VM is the unique ability of highly aggressive tumor cells, but not of poorly aggressive cells, to mimic the presence and function of endothelial cells and form matrix-rich networks de novo, which are able to convey blood plasma and red blood cells (6-8). In VM, the blood vessels wall is lined exclusively by tumor cells, without the participation of endothelial cells $(9,10)$. As a secondary circulation system, VM has been recognized as an important form of vasculogenic structure in solid tumors, including melanoma, breast cancer, hepatocellular carcinoma, prostate cancer, clear cell renal cell carcinoma, glioblastoma, gastric adenocarcinoma, colorectal cancer and gestational choriocarcinoma (6,11-19). In ovarian cancer, VM has been correlated with poor prognosis, low survival and increased risk of cancer recurrence (6). However, the mechanisms involved in the generation of VM in ovarian cancer remain obscure.

Human chorionic gonadotropin (HCG), a hormone of trophoblastic origin, was considered to be a proangiogenic factor (20). HCG increases uterine arterial blood flow and stimulates angiogenesis in the ovary by stimulating the proliferation of vascular endothelial cells and the expression of vascular endothelial growth factor (VEGF) (21-23). HCG induces neovascularization in placenta during pregnancy (24). In ovarian cancer, the HCG protein and its receptor, luteinizing hormone receptor (LHR), exhibited positive expression (25). HCG is also 'ectopically' expressed in numerous malignant tumors such as endometrial carcinoma and ovarian, testicular and breast cancer (26-30). A previous study by the present authors demonstrated that 
HCG promotes VM formation in three-dimensional cultures of OVCAR-3 cells, and anoxia could promote VM formation via activation of hypoxia-inducible factor-1 (31). Therefore, the present authors hypothesize that HCG may be important in the development of VM in ovarian cancer.

To further investigate the role of chorionic gonadotropin, beta polypeptide 5 (CGB5, which is the fifth subunit of $\beta$-HCG and was identified as the key part of HCG) in ovarian cancer VM formation in vivo, a tumor formation model in vivo was constructed in the present study, and the effect of HCG binding to its receptor in VM formation was investigated in vivo. The results demonstrated the role of CGB5 in VM formation in vivo, and support a novel approach for ovarian cancer therapy.

\section{Materials and methods}

Cell lines and cell culture. The human epithelial ovarian cancer cell line OVCAR-3 and the human choriocarcinoma cell line BeWo were purchased from the American Type Culture Collection (Manassas, VA, USA). OVCAR-3 cells were cultured at $37^{\circ} \mathrm{C}$ and $5 \% \mathrm{CO}_{2}$, in RPMI-1640 medium (Gibco; Thermo Fisher Scientific, Inc., Waltham, MA, USA) supplemented with $10 \%$ fetal bovine serum (FBS; Gibco; Thermo Fisher Scientific, Inc.). BeWo cells were cultured in F-12 medium (Gibco; Thermo Fisher Scientific, Inc.) supplemented with $15 \%$ FBS.

CGB5 expression and small interfering RNA (siRNA) lentivirus production and infection. Human CGB complementary DNA (cDNA; accession no. NM_033043.1) was obtained from a human fetal ovary library, and subcloned into the pLenti6/entre-EGFP vector (Invitrogen; Thermo Fisher Scientific, Inc.), which led to pLenti/EGFP-CGB5. The siRNA template sequence 5'-AGCAGCAACAGCAGC AGCCTC-3', which targeted CGB5, was constructed into the pcDNA $^{\text {TM }} 6.2-\mathrm{GW} / \mathrm{EmGFP}-\mathrm{miR}$ vector (Invitrogen; Thermo Fisher Scientific, Inc.), and the construct was named pGFP-CGB5_siR. A total of $3 \mu \mathrm{g}$ pLenti/EGFP-CGB5 vector, pGFP-CGB5_siR or pLenti6/entre-EGFP (which served as a control) and $9 \mu \mathrm{g}$ ViraPower ${ }^{\mathrm{TM}}$ Packaging Mix (Invitrogen; Thermo Fisher Scientific, Inc.) were used to co-transfect $5 \times 10^{6}$ 293FT cells (Thermo Fisher Scientific, Inc.) with Lipofectamine 2000 (Invitrogen; Thermo Fisher Scientific, Inc.), according the manufacturer's protocol. After transfection for $48 \mathrm{~h}$, the supernatant containing the lentiviruses was harvested, centrifuged and stored at $-80^{\circ} \mathrm{C}$. For infection, the cells were seeded at $1 \times 10^{5}$ cells/well into a 6 -well plate and cultured overnight, and then lentiviruses were added. After $24 \mathrm{~h}$ of infection, $10 \mathrm{ng}$ blastin (Invitrogen; Thermo Fisher Scientific, Inc.) was added to the cells to obtain a stable cell clone, and the cells were then sorted by flow cytometry.

Animals and experiments. BALB/c female nude mice were purchased from the laboratory animal center of the Chinese Academy of Sciences (Beijing, China). Mice that were 4-6 weeks old and had an average body weight of 18-20 g were used in the study. The experimental procedures were performed according to the standards established by the Guide for the Care and Use of Laboratory Animals of the National
Institutes of Health (32). For tumor formation in vivo, 36 mice were randomly divided into 6 groups, and injected with normal OVCAR-3 cells, control vector-transfected OVCAR-3 cells, CGB5-overexpressing OVCAR-3 cells, CGB5-knockdown OVCAR-3 cells or BeWo cells (6 mice/group). Tumors were allowed to grow for 2-6 weeks after tumor inoculation, and the mice were then sacrificed by cervical decapitation. Next, tumors were subjected to histopathological examination, transmission electron microscopy observation and reverse transcription-polymerase chain reaction (RT-PCR) analysis.

Hematoxylin and eosin $(H \& E)$ staining and cluster of differentiation (CD)34-periodic acid-Schiff (PAS) dual staining. The tumor xenograft specimens were fixed in $10 \%$ neutral buffered formalin and paraffin-embedded. Paraffin-embedded specimens were cut into serial $6-\mu \mathrm{m}$ sections to be placed on slides. The sections were rehydrated through graded alcohols into water. Endogenous peroxidase was blocked with $3 \%$ hydrogen peroxide in $50 \%$ methanol for $10 \mathrm{~min}$ at room temperature. Upon rehydration, the sections were washed with phosphatebuffered saline (PBS) for $15 \mathrm{~min}$ and then pre-treated with $0.01 \mathrm{~mol} / 1$ citrate acid buffer $(\mathrm{pH} 6.0)$ for $20 \mathrm{~min}$ at $100^{\circ} \mathrm{C}$ in a microwave oven. After rinsing with PBS, slides were incubated with primary antibodies against CD34 (sc-74499, Santa Cruz Biotechnology, Inc., Dallas, TX, USA; 1:100 dilution) overnight. After washing in PBS for three times, the slides were incubated with peroxidase-conjugated donkey anti-rabbit antibody (P0448, Dako North America, Inc., Carpinteria, CA, USA; 1:100 dilution) for $30 \mathrm{~min}$. The reactions were visualized with diaminobenzidine (EnVision; Dako North America, Inc.) and counterstained with hematoxylin (EnVision; Dako North America, Inc). The CD34-immunohistochemically stained sections were further stained with PAS, followed by counterstaining with hematoxylin. These double-stained sections were used for observing microvascular and VM structures. Quantification of VM was performed as follows: VM channels and endothelium-dependent vessels in the H\&E-stained sections were counted under a microscope using x400 magnification, while CD34-PAS dual staining sections were viewed at X400 magnification. The channels defined as VM were lined by PAS-positive material, with red cells in the center of the channels, but were not lined by CD34-positive endothelial cells. The mean numbers of VM in 10 areas were calculated as the VM channel density for each section.

Transmission electron microscopy observation. Fresh tumor xenograft tissues $\left(0.5-\mathrm{mm}^{3}\right)$ were fixed in cold $2.5 \%$ glutaraldehyde in $0.1 \mathrm{~mol} / 1$ sodium cacodylate buffer and post-fixed in a solution of $1 \%$ osmium tetroxide, then dehydrated and embedded in a standard manner (33). The specimens were then embedded, sectioned and stained by routine means for analysis with a transmission electron microscope (34).

Immunohistochemical staining. The paraffin sections were deparaffinized and rehydrated according to the method described above. After rinsing with PBS, the slides were incubated overnight with primary antibodies against Ki-67 (mouse monoclonal; sc-23900, Santa Cruz Biotechnology, Inc.; 1:100 dilution), VEGF (sc-7269, mouse monoclonal; Santa Cruz Biotechnology, Inc., 1:50), factor VIII (goat 
Table I. Sequences of the primers used in reverse transcription-polymerase chain reaction.

\begin{tabular}{lll}
\hline Gene name & Accession no. & \\
\hline CGB5 & NM_033043.1 & Sequence $\left(5^{\prime}-3^{\prime}\right)$ \\
CD31 & NM_000442.4 & Forward: CTACTGCCCCACCATGACC \\
& & Reverse: ATGGACTCGAAGCGCACATC \\
Factor VIII & NM_000132.3 & Forward: ATTGCAGTGGTTATCATCGGAGTG \\
& & Reverse:CTCGTTGTTGGAGTTCAGAAGTGG \\
LHR & NM_000610.3 & Forward: ATCGAGGGTCTCGGGGATGCG \\
GAPDH & & Reverse: TGCGAAGAGTGCTGCGAATGCT \\
& NM_001256799.1 & Forward: TGGCTGCTGTAAACGTCGGG \\
& & Reverse: GGAGAGCTGTACCTTGACAGTG \\
\hline
\end{tabular}

CGB5, chorionic gonadotropin, beta polypeptide 5; CD, cluster of differentiation; LHR, luteinizing hormone receptor; GAPDH, glyceraldehyde 3-phosphate dehydrogenase.

polyclonal; sc-33584, Santa Cruz Biotechnology, Inc.; 1:100 dilution), $\beta$-HCG (sc-7822, mouse monoclonal; Santa Cruz Biotechnology, Inc.; 1:100 dilution), LHR (sc-293165, mouse monoclonal; Santa Cruz Biotechnology, Inc.; 1:100 dilution) and CD31 (rabbit polyclonal; sc-8306, Santa Cruz Biotechnology, Inc.; 1:100 dilution). After washing in PBS for three times, the slides were incubated with peroxidase-conjugated donkey anti-mouse or anti-rabbit antibody (P0447 and P0448, respectively, Dako North America, Inc.; both 1:100 dilution) for $30 \mathrm{~min}$. Negative controls were prepared by replacing the primary antibody with Tris-buffered saline. The reactions were visualized by diaminobenzidine and counterstained with hematoxylin.

$R N A$ isolation and RT-PCR. Total RNA was isolated from the tumor xenograft tissues using TRIzol (Invitrogen; Thermo Fisher Scientific, Inc.). First-strand cDNA was synthesized from $20 \mu 1$ total RNA using oligo(dT)18 primers and reverse transcriptase (Promega Corporation, Madison, WI, USA). RT-PCR was conducted using PCR Master Mix (Promega Corporation) with an initial denaturing step at $94^{\circ} \mathrm{C}$ for $5 \mathrm{~min}$, followed by 20 cycles at $94^{\circ} \mathrm{C}$ for $45 \mathrm{sec}, 58^{\circ} \mathrm{C}$ for $45 \mathrm{sec}$ and $72^{\circ} \mathrm{C}$ for $45 \mathrm{sec}$, and a further extension at $72^{\circ} \mathrm{C}$ for $10 \mathrm{~min}$. Glyceraldehyde 3 -phosphate dehydrogenase was used as an internal control. The sequences of the primers are indicated in Table I.

Detection of secreted $\beta$-HCG by enzyme-linked immunosorbent assay (ELISA). The concentrations of $\beta$-HCG released in the supernatants of the cell cultures were measured by specific human $\beta$-HCG ELISA, according to the manufacturer's protocol (BD Pharmingen, San Diego, CA, USA). Briefly, cells in $100 \mu \mathrm{l}$ medium were seeded at $5 \times 10^{3}$ cells/well onto 96 -well plates, and transfected with different reagents, as described earlier. At the appropriate time, $100 \mu 1$ supernatants were harvested for ELISA.

Statistical analysis. All experiments were repeated $\geq 3$ times. All numerical data were presented as the mean \pm standard deviation. Data were analyzed using the two-tailed $t$ test. $\mathrm{P}<0.05$ was considered to indicate a statistically significant difference.

\section{Results}

CGB5 promotes tumor xenografts formation in vivo. To clarify if CGB5 affected VM formation and tumor development in vivo, the CGB5-expression vector and the siRNA vector targeting CGB5 were transfected into OVCAR-3 cells. Stable expression cell lines were obtained, and the expression of CGB5 at the messenger RNA (mRNA) level was effectively upregulated and downregulated, respectively, in OVCAR-3 cells, as detected by RT-PCR (Fig. 1A and B). Secreted $\beta$-HCG was measured in the supernatant of OVCAR-3 cells (Fig. 1C). Xenografts were established using these cells, which were resuspended at a density of $1 \times 10^{7}$ cells $/ \mathrm{ml}$, and $200 \mu \mathrm{l}$ of this cell suspension was injected subcutaneously into nude mice. BeWo cells with high expression of $\beta-\mathrm{HCG}$ were used as a positive control (Fig. 1D). The tumors appeared gradually in the subcutaneous area of the right armpit of the mice following inoculation. After 2-6 weeks, tumors had grown to an average size of $1-2 \mathrm{~cm}^{3}$. The tumor formation rates of the nude mouse xenografts were $100.0 \%(6 / 6)$ for CGB5-overexpressing OVCAR-3 and BeWo cells, $83.3 \%$ $(5 / 6)$ for normal or control vector-transfected OVCAR-3 cells and $33.3 \%$ (2/6) for CGB5-knockdown OVCAR-3 cells. The rates of tumor growth were also different, with tumors derived from BeWo and CGB5-overexpressing OVCAR-3 injected cells growing faster than tumors derived from CGB5-knockdown OVCAR-3 cells (Fig. 1E). In addition, the cell proliferation marker Ki-67 was detected by immunohistochemical staining, thus supporting such phenomenon (Fig. 1F). These data indicated that CGB5 may promote cell proliferation and tumor growth in ovarian cancer.

The effect of CGB5 on VMformation in tumor xenografts. H\&E staining and CD34-PAS dual staining were used to observe the morphology characteristic of VM in tumor xenografts. Based on H\&E staining, spaces filled with red blood cells, which were completely surrounded by cancer cells, were observed (Fig. 2A a-e). Furthermore, staining of the endothelial cell marker CD34 was used to identify the endothelium in cancer tissue sections, while PAS staining was used to determine the basement 
A
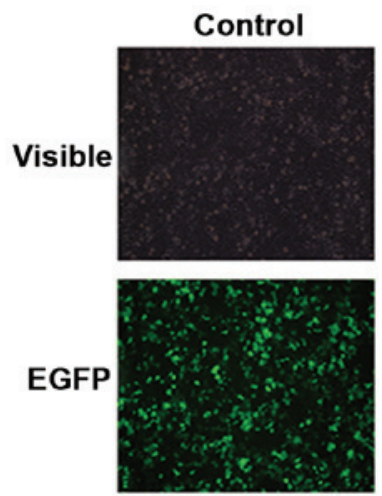

B

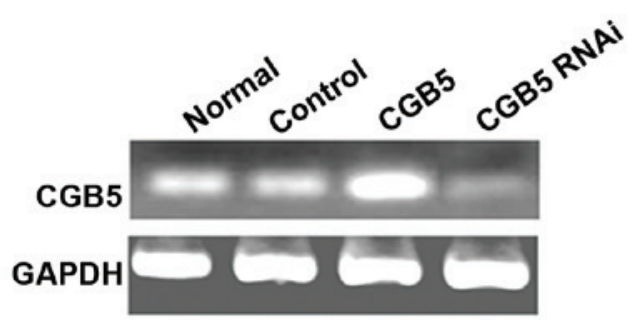

D
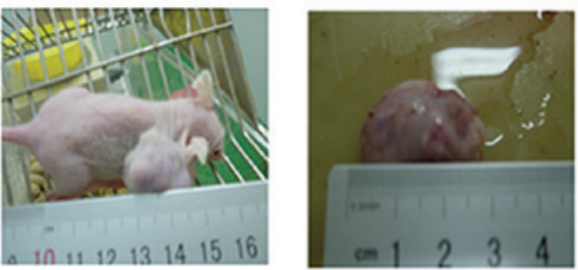

CGB5
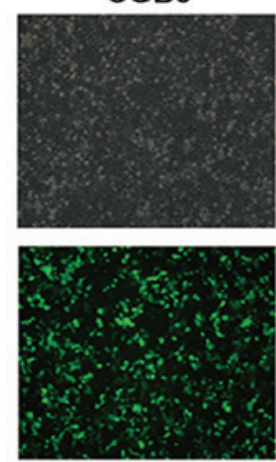

C
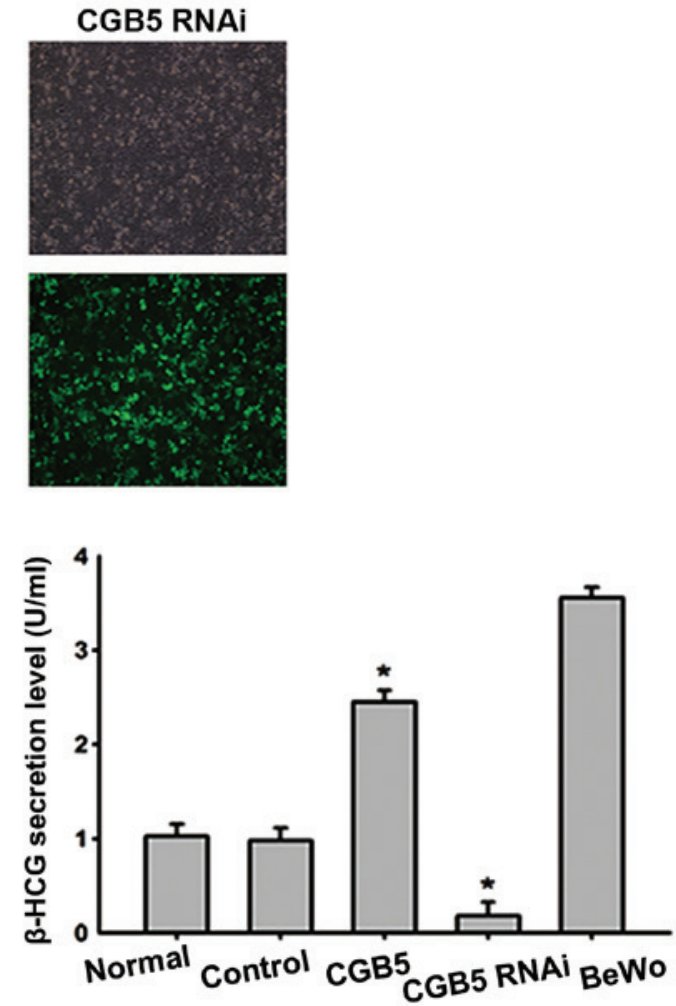

$\mathbf{E}$

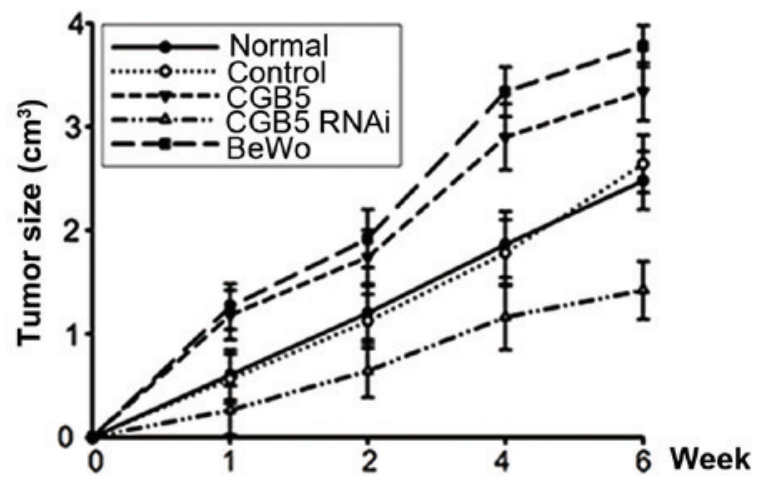

$\mathbf{F}$

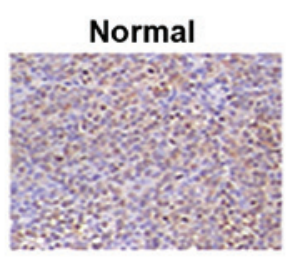

Control

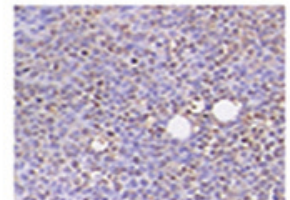

CGB5

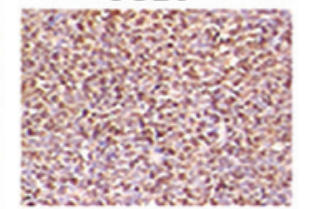

CGB5 RNAi

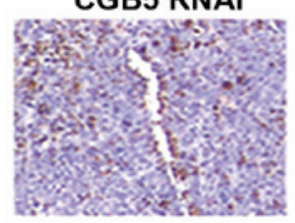

BeWo

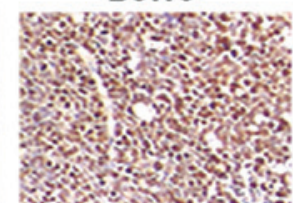

Figure 1. Effect of CGB5 on tumor xenografts formation in vivo. (A) Lentivirus vector expressing CGB5 and small interfering RNA vector were infected in OVCAR-3 cells. EGFP expression demonstrated that the above vectors were stably infected in these cells. Control, pLenti6/entre-EGFP-infected cells; CGB5, CGB5-overexpressing cells; and CGB5 RNA interference, CGB5-knockdown cells. The BeWo cell line, which secrets high levels of $\beta$-HCG, was used as a positive control. Magnification, x40. (B) Reverse transcription-polymerase chain reaction was used to determine the messenger RNA levels of CGB5 in the stably transfected cells. (C) The supernatant of these stably transfected cells was collected, and the $\beta$-HCG levels were detected by enzyme-linked immunosorbent assay. "P<0.05 vs. normal cells. (D) Cells were injected subcutaneously into the nude mice, and the tumors appeared gradually in the subcutaneous area of the right armpit of the mice at 2-6 weeks post-inoculation. (E) The speed of tumor growth was measured at 1,2, 4 and 6 weeks after injection. (F) The cell proliferation marker Ki-67 was detected by immunohistochemical analysis. Magnification, x400. CGB5, chorionic gonadotropin, beta polypeptide 5; GAPDH, glyceraldehyde 3-phosphate dehydrogenase; EGFP, enhanced green fluorescent protein; RNAi, RNA interference; HCG, human chorionic gonadotropin.

membrane of tumor blood vessels (Fig. 2A f-j). The channel consisted of tumor cells that were positive for PAS and negative for CD34. Following statical analysis in 10 fields, the average numbers of blood supply patterns in tumors were defined as the number of VM in one section. Compared with the normal cells group, VM channels in xenografts were significantly increased in CGB5-overexpressing OVCAR-3 cells and in the BeWo cell group, while they were significantly reduced in the CGB5-knockdown OVCAR-3 cells group (Fig. 2B). There were cavities in the central structure of tumor nests, as clearly 
A
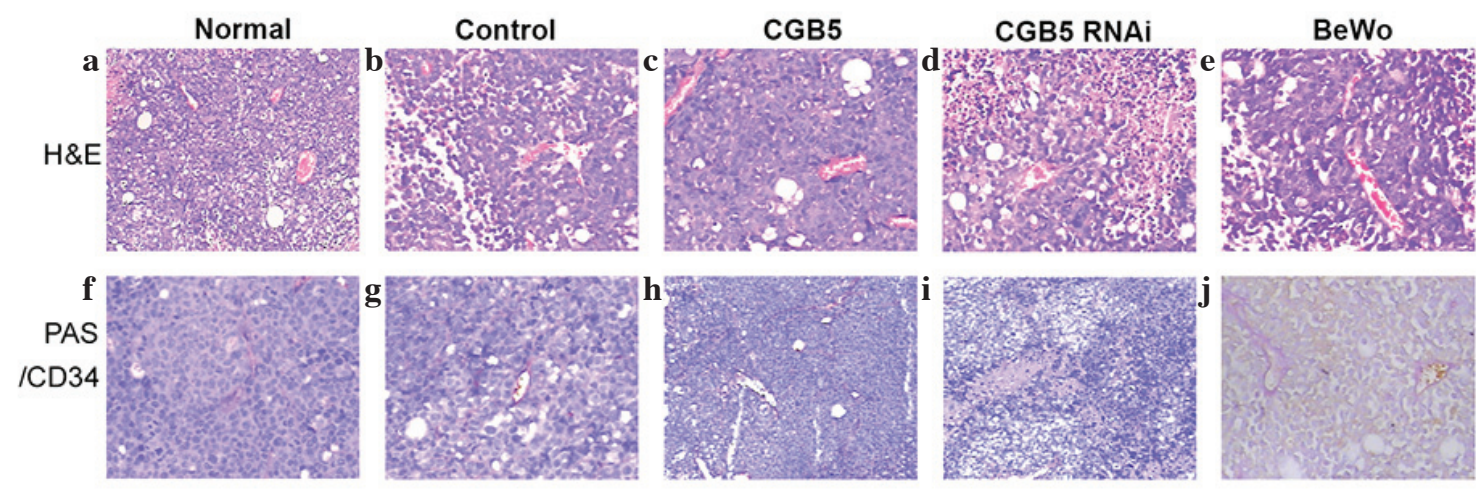

B

a

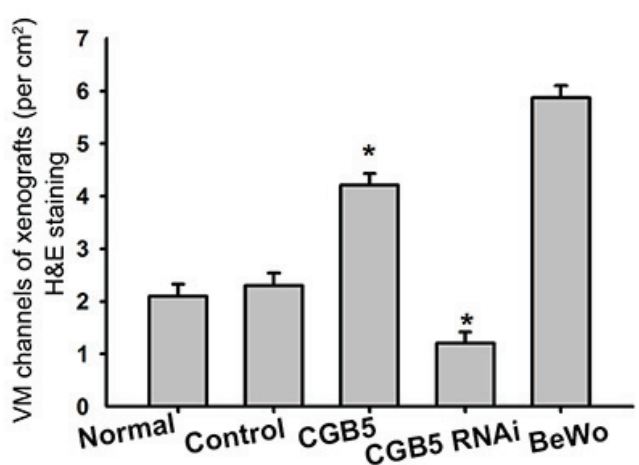

b

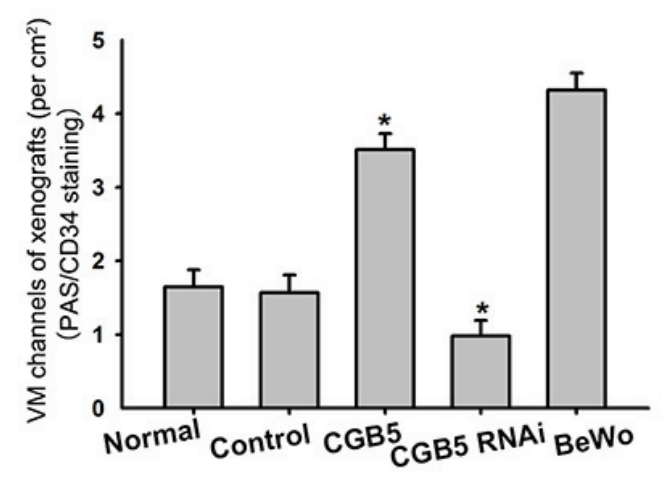

C
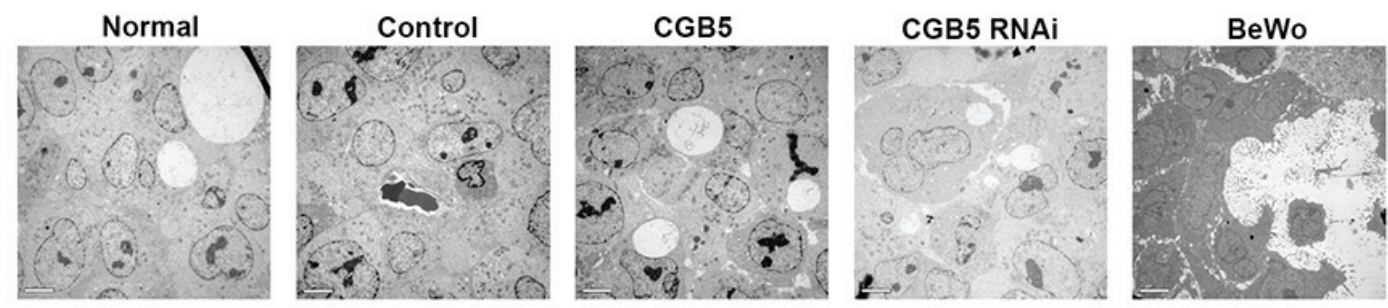

Figure 2. Effect of CGB5 on VM formation by H\&E and CD34-PAS staining. (A) After tumor growth to $1-2 \mathrm{~cm}^{3}$, the tumors were collected and cut into serial 6- $\mu \mathrm{m}$ sections. (a-e) H\&E staining was used to detect VM formation. (f-j) PAS staining was used to identify matrix-associated vascular channels, while CD34 staining was used to identify the endothelium in the cancer tissue sections. PAS-positive and CD34-negative channels were considered as VM. (B) VM quantification was performed as follows: (a) VM channels and endothelium-dependent vessels in the H\&E-stained sections were counted using X400 magnification, and (b) CD34-PAS dual staining sections were viewed at $\mathrm{x} 400$ magnification. ${ }^{*} \mathrm{P}<0.05$ vs. normal cells. (C) Transmission electron microscopy examination. CGB5, chorionic gonadotropin, beta polypeptide 5; GAPDH, glyceraldehyde 3-phosphate dehydrogenase; RNAi, RNA interference; HCG, human chorionic gonadotropin; VM, vasculogenic mimicry; H\&E, hematoxylin and eosin; PAS, periodic acid-Schiff.

analyzed by transmission electron microscopy. Single, double, or multiple red blood cells-containing cavities structures could be observed in the choriocarcinoma specimens, according to their cell morphology. The number of cavities was much higher in CGB5-overexpressing tumor nests than in normal ovarian cancer specimens (Fig. 2C). These results indicated that HCG may promote the process of VM formation in ovarian cancer.

CGB5 promotes vascular marker expression in tumor xenografts. To further confirm VM formation in the tumor xenografts, the vascular markers CD31, VEGF and factor VIII were detected. The mRNA levels of CD31, VEGF and factor VIII were increased in the CGB5-overexpressing cell group, whereas they were decreased in the CGB5-knockdown cell group (Fig. 3A). The results of immunohistochemical staining of CD31, VEGF and factor VIII exhibited the same tendency as the mRNA results (Fig. 3B). Compared with normal cells, the expression of vascular markers was higher in CGB5-overexpressing OVCAR-3 and BeWo cells. By contrast, the expression of these vascular markers was weak and focal in the CGB5-knockdown OVCAR-3 cell group (Fig. 3C).

Change in LHR expression in tumor xenografts. Previous studies indicated that CGB5 may promote VM and tumor formation in vitro (31). However, the effect of CGB5 in the pathway mediated by LHR binding remains unknown. In the present study, the mRNA expression levels of LHR changed following the same tendency than CGB5 (Fig. 4A). Furthermore, immunochemistry demonstrated that LHR expression was increased in the CGB5-overexpressing OVCAR-3 cell group, while it was downregulated in the CGB5-knockdown OVCAR-3 cell group (Fig. 4B and C). These data indicated that CGB5 promotes VM formation in ovarian carcinoma via activation of LHR signal transduction. 
A

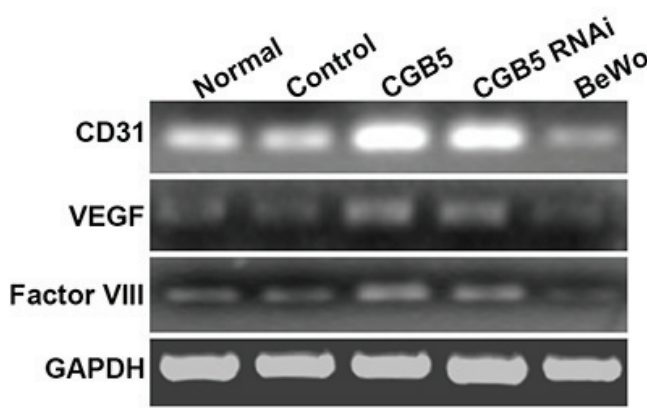

C
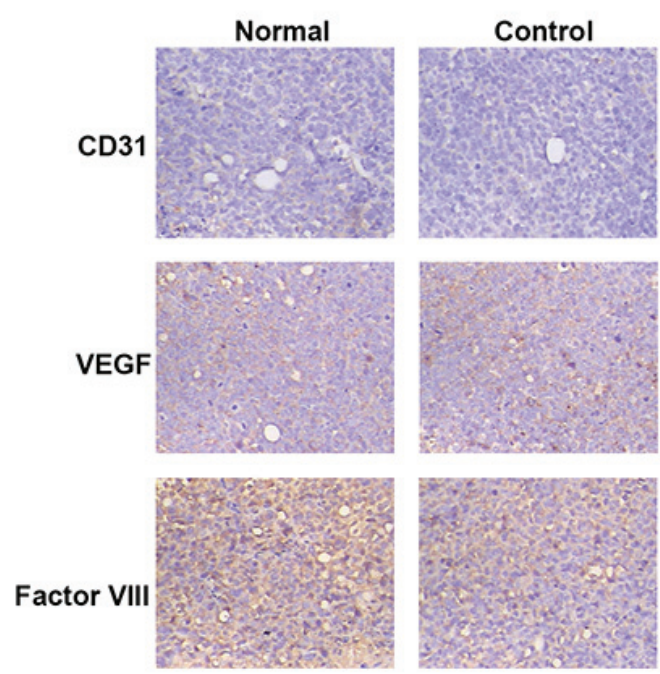

B
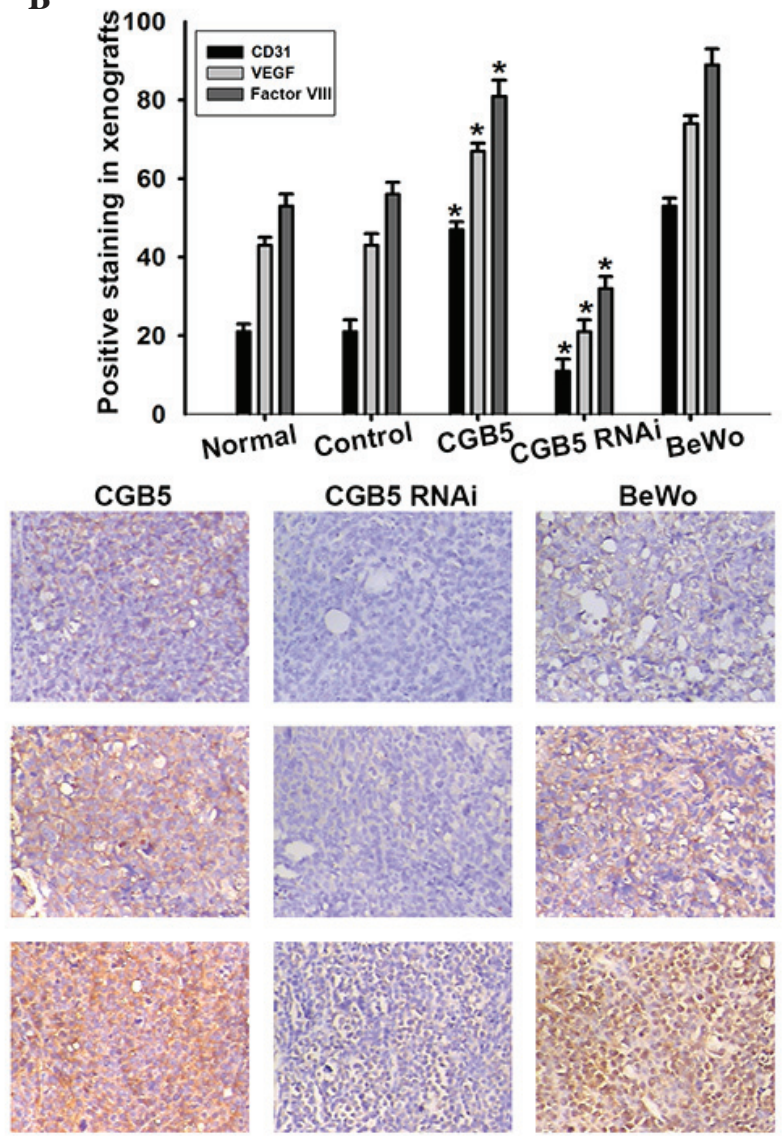

Figure 3. Expression of vascular markers in tumor xenografts. (A) Reverse transcription-polymerase chain reaction was used to determine the messenger RNA levels of the vascular markers CD31, VEGF and factor VIII in tumor tissues. (B) Statistical analysis of CD31, VEGF and factor VIII expression. "P<0.05 vs. normal cells. (C) Immunohistochemical analysis was used to detect CD31, VEGF and factor VIII expression. Magnification, x400. CGB5, chorionic gonadotropin, beta polypeptide 5; GAPDH, glyceraldehyde 3-phosphate dehydrogenase; VEGF, vascular endothelial growth factor; RNAi, RNA interference.

A

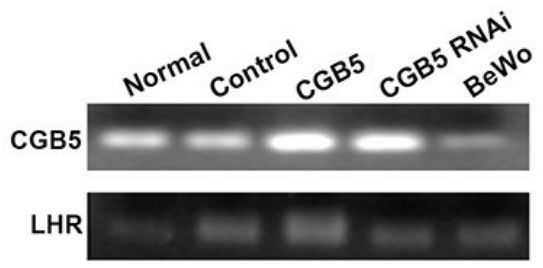

C
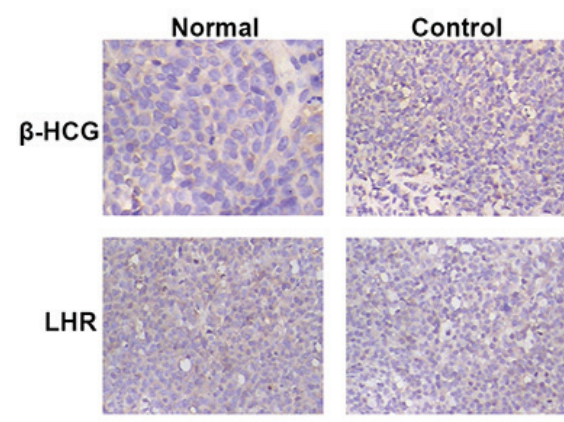

B

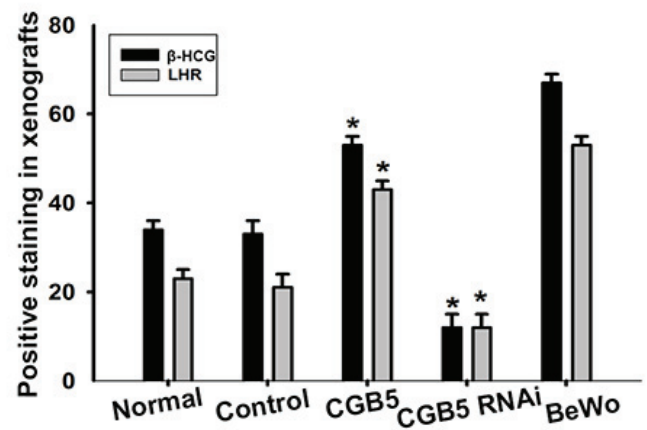

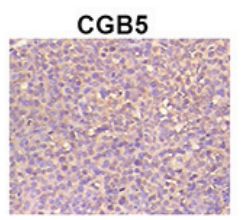

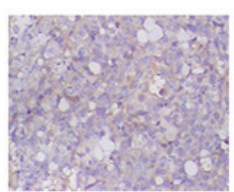

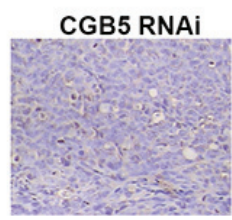
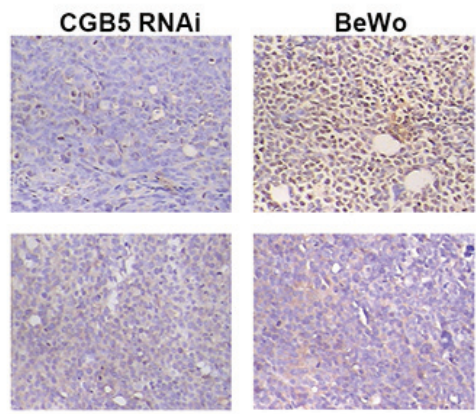

Figure 4. Expression of LHR in tumor xenografts. (A) Messenger RNA levels of CGB5 and LHR in tumor tissues were determined by reverse transcriptionpolymerase chain reaction. (B) Statistical analysis of CGB5 and LHR expression. ${ }^{*} \mathrm{P}<0.05$ vs. normal cells. (C) Immunohistochemistry was used to detect CGB5 and LHR expression. CGB5, chorionic gonadotropin, beta polypeptide 5; HCG, human chorionic gonadotropin; LHR, luteinizing hormone receptor. 


\section{Discussion}

HCG, which is primarily produced by the placenta, was considered to be a proangiogenic factor in recent reports (35). In the present study, CGB5 (the fifth subunit of $\beta$-HCG, which was identified as the key part of HCG) was used to investigate the role of HCG in VM formation. The current study identified that CGB5 may increase tumor growth, VM formation and LHR expression. These data indicated that, in ovarian carcinoma, CGB5 was the promoter of VM formation and tumor growth via the activation of LHR signal transduction.

$\mathrm{HCG}$, a heterodimeric glycoprotein hormone, is composed of a single $\alpha$-subunit and a target-specific $\beta$-subunit, which is encoded by a multigene cluster composed of six homologous sequences $(\beta 1, \beta 2, \beta 3, \beta 5, \beta 7$ and $\beta 8)(24,36,37)$; however, only the heterodimers containing $\beta 5, \beta 3$ or $\beta 8$ are transcriptionally active $(37,38)$. Since the expression of the $\beta 5$-subunit is the highest of all subunits (37), the present study selected CGB5 as the potential target gene in VM formation. It has been reported that HCG can increase uterine arterial blood flow and stimulate angiogenesis in the ovary by stimulating vascular endothelial cell proliferation and VEGF expression (21-22). HCG can also prevent luteolysis by maintaining luteal blood flow (31). In early pregnancy, HCG expression is associated with endometrial angiostimulation, since HCG increases blood supply and alters the uterine vasculature via vasodilatation, thus increasing the permeability, development and maturation of newly formed blood vessels (25). It has been reported that HCG exerts its effect possibly by interacting with its LHR receptor (39). The present study identified that CGB5 overexpression promoted tumor growth and formation, which was accompanied by an increase in LHR expression.

VM describes the unique ability of highly aggressive tumor cells to mimic the presence and function of endothelial cells, thus forming matrix-rich networks de novo, which could convey blood plasma and red blood cells (6-8). Based on H\&E staining, channels which PAS-positive material and red cells in the center of the channels but CD34-negative endothelial cells may be identified as VM in vivo. The present study suggested that CGB5 may promote OVCAR-3 cells tumor growth and VM formation in tumor xenografts. It has been reported that certain ovarian cancer cells may differentiate into endothelial-like cells. To further identify the formation of VM, vascular markers, including CD31, factor VIII and VEGF, were also detected in OVCAR-3 cells in vivo. The expression of CD31, factor VIII and VEGF followed the same tendency as the levels of CGB5 in these cells.

In conclusion, ovarian cancer is a silent killer, and the present results provide clearly in vivo evidence that HCG is important in the formation of VM. Therefore, it is possible to speculate that the use of anti-HCG therapeutic targeting may provide a novel opportunity to circumvent tumors that express HCG, such as ovarian cancer and choriocarcinoma.

\section{Acknowledgements}

The present study was supported by the National Natural Science Foundation of China (Beijing, China; grant no. 30801226).

\section{References}

1. Zhang B, Barekati Z, Kohler C, Radpour R, Asadollahi R, Holzgreve $\mathrm{W}$ and Zhong XY: Proteomics and biomarkers for ovarian cancer diagnosis. Ann Clin Lab Sci 40: 218-225, 2010.

2. Wang JY, Sun T, Zhao XL, Zhang SW, Zhang DF, Gu Q, Wang XH, Zhao N, Qie S and Sun BC: Functional significance of VEGF-a in human ovarian carcinoma: Role in vasculogenic mimicry. Cancer Biol Ther 7: 758-766, 2008.

3. Zhang S, Zhang D and Sun B: Vasculogenic mimicry: Current status and future prospects. Cancer Lett 254: 157-164, 2007.

4. Vartanian AA, Burova OS, Stepanova EV, Baryshnikov AY and Lichinitser MR: Melanoma vasculogenic mimicry is strongly related to reactive oxygen species level. Melanoma Res 17: 370-379, 2007.

5. Folkman J: Fundamental concepts of the angiogenic process. Curr Mol Med 3: 643-651, 2003.

6. Maniotis AJ, Folberg R, Hess A, Seftor EA, Gardner LM, Pe'er J, Trent JM, Meltzer PS and Hendrix MJ: Vascular channel formation by human melanoma cells in vivo and in vitro: Vasculogenic mimicry. Am J Pathol 155: 739-752, 1999.

7. Sun W, Fan YZ, Zhang WZ and Ge CY: A pilot histomorphology and hemodynamic of vasculogenic mimicry in gallbladder carcinomas in vivo and in vitro. J Exp Clin Cancer Res 30: 46, 2011.

8. Hess AR, Seftor EA, Seftor RE and Hendrix MJ: Phosphoinositide 3-kinase regulates membrane Type 1-matrix metalloproteinase (MMP) and MMP-2 activity during melanoma cell vasculogenic mimicry. Cancer Res 63: 4757-4762, 2003.

9. Sun B, Zhang D, Zhang S, Zhang W, Guo H and Zhao X: Hypoxia influences vasculogenic mimicry channel formation and tumor invasion-related protein expression in melanoma. Cancer Lett 249: 188-197, 2007.

10. Sood AK, Seftor EA, Fletcher MS, Gardner LM, Heidger PM, Buller RE, Seftor RE and Hendrix MJ: Molecular determinants of ovarian cancer plasticity. Am J Pathol 158: 1279-1288, 2001.

11. Shirakawa K, Wakasugi H, Heike Y, Watanabe I, Yamada S, Saito K and Konishi F: Vasculogenic mimicry and pseudo-comedo formation in breast cancer. Int J Cancer 99: 821-828, 2002.

12. Guzman G, Cotler SJ, Lin AY, Maniotis AJ and Folberg R: A pilot study of vasculogenic mimicry immunohistochemical expression in hepatocellular carcinoma. Arch Pathol Lab Med 131: 1776-1781, 2007.

13. Sharma N, Seftor RE, Seftor EA, Gruman LM, Heidger PM Jr, Cohen MB, Lubaroff DM and Hendrix MJ: Prostatic tumor cell plasticity involves cooperative interactions of distinct phenotypic subpopulations: Role in vasculogenic mimicry. Prostate 50: 189-201, 2002.

14. Vartanian AA, Stepanova EV, Gutorov SL, Solomko ESh, Grigorieva IN, Sokolova IN, Baryshnikov AY and Lichinitser MR: Prognostic significance of periodic acid-Schiff-positive patterns in clear cell renal cell carcinoma. Can J Urol 16: 4726-4732, 2009.

15. El Hallani S, Boisselier B, Peglion F, Rousseau A, Colin C, Idbaih A, Marie Y, Mokhtari K, Thomas JL, Eichmann A, et al: A new alternative mechanism in glioblastoma vascularization: Tubular vasculogenic mimicry. Brain 133: 973-982, 2010.

16. Li M, Gu Y, Zhang Z, Zhang S, Zhang D, Saleem AF, Zhao X and Sun B: Vasculogenic mimicry: A new prognostic sign of gastric adenocarcinoma. Pathol Oncol Res 16: 259-266, 2010.

17. Baeten CI, Hillen F, Pauwels P, de Bruine AP and Baeten CG: Prognostic role of vasculogenic mimicry in colorectal cancer. Dis Colon Rectum 52: 2028-2035, 2009.

18. Shih IeM: Trophoblastic vasculogenic mimicry in gestational choriocarcinoma. Mod Pathol 24: 646-652, 2011.

19. Sood AK, Fletcher MS, Zahn CM, Gruman LM, Coffin JE, Seftor EA and Hendrix MJ: The clinical significance of tumor cell-lined vasculature in ovarian carcinoma: Implications for anti-vasculogenic therapy. Cancer Biol Ther 1: 661-664, 2002.

20. Zygmunt M, Herr F, Keller-Schoenwetter S, Kunzi-Rapp K, Münstedt K, Rao CV, Lang U and Preissner KT: Characterization of human chorionic gonadotropin as a novel angiogenic factor. J Clin Endocrinol Metab 87: 5290-5296, 2002.

21. Toth P,Li X, Rao CV,Lincoln SR, Sanfilippo JS, Spinnato JA II and Yussman MA: Expression of functional human chorionic gonadotropin/human luteinizing hormone receptor gene in human uterine arteries. J Clin Endocrinol Metab 79: 307-315, 1994.

22. Wulff C, Dickson SE, Duncan WC and Fraser HM: Angiogenesis in the human corpus luteum: Simulated early pregnancy by HCG treatment is associated with both angiogenesis and vessel stabilization. Hum Reprod 16: 2515-2524, 2001. 
23. Berndt S, Perrier d'Hauterive S, Blacher S, Péqueux C, Lorquet S, Munaut C, Applanat M, Hervé MA, Lamandé N, Corvol P, et al: Angiogenic activity of human chorionic gonadotropin through LH receptor activation on endothelial and epithelial cells of the endometrium. FASEB J 20: 2630-2632, 2006.

24. Michel RM, Aguilar JL and Arrieta O: Human chorionic gonadotropin as an angiogenic factor in breast cancer during pregnancy. Med Hypotheses 68: 1035-1040, 2007.

25. Szajnik M, Nowak-Markwitz E, Szczepański MJ and Spaczyński M: Assessment of expression of luteinizing hormone (LH)/human chorionic gonadotropin (hCG) receptor (LH/hCGR) and hCG protein in ovarian cancer tissues. Ginekol Pol 78: 939-943, 2007 (In Polish).

26. Muller CY and Cole LA: The quagmire of hCG and hCG testing in gynecologic oncology. Gynecol Oncol 112: 663-672, 2009.

27. Lempiäinen A, Stenman UH, Blomqvist C and Hotakainen K Free beta-subunit of human chorionic gonadotropin in serum is a diagnostically sensitive marker of seminomatous testicular cancer. Clin Chem 54: 1840-1843, 2008.

28. Iles RK, Delves PJ and Butler SA: Does hCG or hCG $\beta$ play a role in cancer cell biology? Mol Cell Endocrinol 329: 62-70, 2010.

29. Daniel KD, Kim GY, Vassiliou CC, Jalali-Yazdi F, Langer R and Cima MJ: Multi-reservoir device for detecting a soluble cancer biomarker. Lab Chip 7: 1288-1293, 2007.

30. Jankowska AG, Andrusiewicz M, Fischer N and Warchol PJ: Expression of hCG and GnRHs and their receptors in endometrial carcinoma and hyperplasia. Int J Gynecol Cancer 20 : 92-101, 2010

31. Su M, Wei W, Xu X, Wang X, Chen C, Su L and Zhang Y: Role of hCG in vasculogenic mimicry in OVCAR-3 ovarian cancer cell line. Int J Gynecol Cancer 21: 1366-1374, 2011.
32. Kavak S, Ayaz L and Emre M: Effects of rosiglitazone with insulin combination therapy on oxidative stress and lipid profile in left ventricular muscles of diabetic rats. Exp Diabetes Res 2012: 905683, 2012.

33. Newton PT, Staines KA, Spevak L, Boskey AL, Teixeira CC, Macrae VE, Canfield AE and Farquharson C: Chondrogenic ATDC5 cells: An optimised model for rapid and physiological matrix mineralisation. Int J Mol Med 30: 1187-1193, 2012.

34. Scimeca M, Orlandi A, Terrenato I, Bischetti S and Bonanno E Assessment of metal contaminants in non-small cell lung cancer by EDX microanalysis. Eur J Histochem 58: 2403, 2014.

35. Brouillet S, Hoffmann P, Chauvet S, Salomon A, Chamboredon S, Sergent F, Benharouga M, Feige JJ and Alfaidy N: Revisiting the role of hCG: new regulation of the angiogenic factor EG-VEGF and its receptors. Cell Mol Life Sci 69: 1537-50, 2012.

36. Hamada AL, Nakabayashi K, Sato A, Kiyoshi K, Takamatsu Y, Laoag-Fernandez JB, Ohara N and Maruo T: Transfection of antisense chorionic gonadotropin beta gene into choriocarcinoma cells suppresses the cell proliferation and induces apoptosis. J Clin Endocrinol Metab 90: 4873-4879, 2005.

37. Bo $\mathrm{M}$ and Boime I: Identification of the transcriptionally active genes of the chorionic gonadotropin beta gene cluster in vivo. J Biol Chem 267: 3179-3184, 1992.

38. Talmadge K, Boorstein WR, Vamvakopoulos NC, Gething MJ and Fiddes JC: Only three of the seven human chorionic gonadotropin beta subunit genes can be expressed in the placenta. Nucleic Acids Res 12: 8415-8436, 1984

39. Meng XL, Rennert OM and Chan WY: Human chorionic gonadotropin induces neuronal differentiation of $\mathrm{PC} 12$ cells through activation of stably expressed lutropin/choriogonadotropin receptor. Endocrinology 148: 5865-5873, 2007. 